\title{
INDIRECT ELISAS BASED ON RECOMBINANT AND AFFINITY-PURIFIED GLYCOPROTEIN E OF AUJESZKY'S DISEASE VIRUS TO DIFFERENTIATE BETWEEN VACCINATED AND INFECTED ANIMALS
}

\author{
O. S. MORENKOV ${ }^{1 *}$, Nadja FODOR ${ }^{2}$ and I. FODOR ${ }^{2,3}$ \\ ${ }^{1}$ Institute of Cell Biophysics, Russian Academy of Sciences, Pushchino, 142292, Russia; \\ ${ }^{2}$ Institute for Biochemistry and Protein Research, Agricultural Biotechnology Centre, \\ Gödöllö, Hungary; ${ }^{3}$ Center for Molecular Biology and Gene Therapy, Loma Linda \\ University, Loma Linda, CA, USA
}

(Received December 9, 1997; accepted May 15, 1998)

\begin{abstract}
Two indirect ELISAs for the detection of antibodies against glycoprotein E (gE) of Aujeszky's disease virus (ADV) in sera have been developed. The rec-gEELISA is based on the E. coli-expressed recombinant protein containing the Nterminal sequences of $\mathrm{gE}$ (aa 1-125) fused with the glutathione S-transferase from Schistosoma japonicum. The affi-gE-ELISA is based on native gE, which was purified from virions by affinity chromatography. The tests were optimised and compared with each other, as well as with the recently developed blocking gEELISA (Morenkov et al., 1997b), with respect to specificity and sensitivity. The recgE-ELISA was less sensitive in detecting ADV-infected animals than the affi-gEELISA (sensitivity $80 \%$ and $97 \%$, respectively), which is probably due to the lack of conformation-dependent immunodominant epitopes on the recombinant protein expressed in E. coli. The specificity of the rec-gE-ELISA and affi-gE-ELISA was rather moderate (90\% and $94 \%$, respectively) because it was necessary to set such cut-off values in the tests that provided a maximum level of sensitivity, which obviously increased the incidence of false positive reactions. Though the indirect ELISAs detect antibodies against many epitopes of $\mathrm{gE}$, the blocking gE-ELISA, which detects antibodies against only one immunodominant epitope of $\mathrm{gE}$, showed a better test performance (specificity $99 \%$ and sensitivity $98 \%$ ). This is most probably due to rather high dilutions of the sera used in the indirect gE-ELISAs (1:30) as compared to the serum dilution in the blocking gE-ELISA (1:2). We conclude that the indirect gE-ELISAs are sufficiently specific and sensitive to distinguish ADVinfected swine from those vaccinated with gE-negative vaccine and can be useful, in particularly affi-gE-ELISA, as additional tests for the detection of antibodies to $\mathrm{gE}$.
\end{abstract}

Key words: Aujeszky's disease virus, recombinant and affinity-purified glycoprotein E, indirect and blocking gE-ELISAs, serological differentiation

\footnotetext{
* Corresponding author: Tel.: + (095)925-59-84; Fax: + (095)924-04-93;

E-mail: morenkov@ibfk.nifhi.ac.ru
} 
Aujeszky's disease (AD) has long been recognised as one of the most economically important viral diseases of swine characterised by an acute and often fatal infection in piglets and by a variety of clinical signs of disease in older pigs, including encephalitis, pneumonia, increased susceptibility to other respiratory pathogens, and abortion (Wittman, 1991). Although vaccination is effective in reducing the circulation of wild $\mathrm{AD}$ virus (ADV) and preventing the illness, it generally does not prevent infection and establishment of latency, and therefore does not lead to the eradication of AD (Wittman, 1991). The advent of genedeleted vaccines for the control of $\mathrm{AD}$ made it possible to differentiate between infected and vaccinated animals. Glycoprotein E (gE)-negative vaccines (Quint et al., 1987; Moormann et al., 1990) in combination with the detection of anti-gE antibodies in sera are most widely used in programs of AD eradication in many countries (Nauwynck and Pensaert, 1994). The majority of gE-assays used in AD eradication programs detect antibodies against one or two epitopes of gE (Eloit et al., 1988; Van Oirschot et al., 1988; Tonelli, 1991; Grom et al., 1992; Morenkov et al., 1997b). However, it is well known that gE displays an antigenic drift, which may be due to the expression of the altered form of $\mathrm{gE}$ or mutations in antigenic determinants of gE (Ben-Porat et al., 1986; Mettenleiter et al., 1987; Katz and Pederson, 1992). Therefore, field ADV strains lacking several epitopes on gE may arise. Moreover, the antibody responses against different epitopes of $g E$ are highly variable in individual pigs (Jacobs and Kimman, 1994; Jacobs et al., 1994), which can result in undetectable levels of antibodies to some gE epitopes. Obviously, the assays detecting antibodies against one or two epitopes may fail to detect swine infected with such abnormal ADV strains and swine that weakly respond to this (these) epitope(s). The assays recognising antibodies to many epitopes of $\mathrm{gE}$ are less dependent on antigenic modifications of $\mathrm{gE}$ and on the variability of epitopespecific immune responses to gE. Indirect ELISAs based on purified intact $\mathrm{gE}$ and baculovirus-expressed recombinant $\mathrm{gE}$, as well as a double-antibody sandwich ELISA using baculovirus-expressed recombinant $\mathrm{gE}$, which detect anti-gE antibodies against many epitopes of $\mathrm{gE}$, have been developed (Mellencamp et al., 1989; Banks et al., 1995; Kimman et al., 1996). Recombinant gE expressed in E. coli was also shown to have a potential value for the detection of gE-directed antibodies in sera in Western blot (Ro et al., 1995).

Recently we described the production of the E. coli-expressed recombinant protein containing the $\mathrm{N}$-terminal sequences of $\mathrm{gE}$ and the purification of intact $\mathrm{gE}$ by affinity chromatography (Morenkov et al., 1997a). Both proteins displayed a strong reactivity with sera from infected animals in Western blot and ELISA and, therefore, were potentially suitable for the development of gE-tests to detect gE-specific antibodies against many epitopes of $\mathrm{gE}$ in sera. In this report, we describe the development of two indirect gE-ELISAs based on a recombinant fragment of $\mathrm{gE}$ expressed in E. coli (rec-gE-ELISA) and on 
affinity-purified native gE (affi-gE-ELISA). These gE-tests were evaluated by comparing them with each other and with the previously developed blocking gEELISA (Morenkov et al., 1997b) with respect to sensitivity and specificity.

\section{Materials and methods}

Sources of sera

Sera from uninfected and infected unvaccinated swine as well as serum samples from uninfected swine vaccinated against various swine viral disorders (classical swine fever, parvovirus disease, transmissible gastro-enteritis, enzootic encephalomyelitis) were obtained from the serum bank of the Institute of Veterinary Medicine (Kiev, Ukraine). Sera from uninfected and infected swine vaccinated with live gE-negative vaccine against $\mathrm{AD}$ (Bartha K61) were kindly provided by Dr. B. Dénes (Central Veterinary Institute, Budapest, Hungary). All the sera were tested initially for the presence of anti-gE antibodies in a commercial gE-ELISA (Svanova Biotech) according to the manufacturer's recommendations. Sera that produced doubtful results in the reference test were not used in the investigation because no decisions about these samples could be made.

\section{Preparation of affinity-purified $g E$}

The preparation and characterisation of monoclonal antibodies (MAbs) against ADV glycoproteins were described (Morenkov et al., 1994a; Morenkov et al., 1997a). MAbs were purified from ascites fluids by ammonium sulphate precipitation followed by ion-exchange chromatography on DEAE-Toyopearl 650M (Oppermann, 1992). Glycoprotein E-specific MAb 75/7 and gB-specific MAb 34/2 were chosen for immobilisation to Sepharose CL-6B in preliminary experiments. The affinity resin was prepared as described (Stults et al., 1989).

The gE-positive ADV strain $\mathrm{K}$ was used for the preparation of affinitypurified gE. The virus was cultivated on BHK-21 cells maintained in Eagle's minimum essential medium supplemented with $10 \%$ calf serum. BHK-21 cells were infected with the virus at a multiplicity of 2-4 PFU per cell. After $48 \mathrm{~h}$, the viral fluid was treated with $0.5 \%$ Triton $\mathrm{X}-100$ for $2 \mathrm{~h}$ at $37^{\circ} \mathrm{C}$ with stirring. The viral fluid was clarified by centrifugation at $5000 \mathrm{~g}$ for $20 \mathrm{~min}$ followed by filtration through a $0.45 \mu \mathrm{m}$ nitrocellulose filter (Millipore). The clarified gEcontaining fluid was passed subsequently through the $\mathrm{gB}$ - and gE-specific affinity columns. The gE-specific column was thoroughly washed with PBS containing $0.5 \mathrm{M} \mathrm{NaCl}$ and $0.5 \%$ Triton $\mathrm{X}-100$. The glycoprotein $\mathrm{E}$ bound to the column was eluted with $0.1 \mathrm{M} \mathrm{Na}$-carbonate buffer $(\mathrm{pH} 11.0)$ and immediately neutralised with $1 \mathrm{M}$ Tris- $\mathrm{HCl}(\mathrm{pH} 7.5)$. 
The purity and concentration of $\mathrm{gE}$ in the eluted material were determined by the gE- and gB-specific two-site "sandwich" assays (Morenkov et al., 1994b) and by indirect ELISA with gE-, gB- and gD-directed MAbs, as well as with sera from infected and uninfected swine vaccinated with gE-negative vaccine (Morenkov et al., 1997a).

\section{Preparation of recombinant $g E$}

The construction of the recombinant plasmid pGG5 that expresses a fragment of gE was described earlier (Morenkov et al., 1997a). The recombinant $\mathrm{gE}$ was expressed as a fused protein composed of 228 amino acids of glutathione S-transferase (GST) from Schistosoma japonicum plus amino acids 1 to 125 of the N-terminal part of gE tagged with 16 amino acids derived from the open reading frame of the intermediate construct and the expression vector. E. coli cells were transformed with pGG5 plasmid and grown in LB broth supplemented with ampicillin $(50 \mu \mathrm{g} / \mathrm{ml})$ at $37^{\circ} \mathrm{C}$. Isopropyl- $\beta$-D-thiogalactopyranoside was added to the culture medium at a final concentration of $1 \mathrm{mM}$ when cell density reached an optical density of $0.5-0.7(600 \mathrm{~nm})$. Growth was continued at $37^{\circ} \mathrm{C}$ for $4 \mathrm{~h}$. After induction, E. coli cells were centrifuged at $5000 \mathrm{~g}$ for $30 \mathrm{~min}$, washed with PBS, resuspended in $0.05 \mathrm{M}$ Tris- $\mathrm{HCl}(\mathrm{pH} \mathrm{8.0)}$ containing $0.02 \mathrm{M}$ EDTA, and treated with lysozyme $(1 \mathrm{mg} / \mathrm{ml})$ for $20 \mathrm{~min}$ at room temperature. After the addition of Triton $\mathrm{X}-100$ and $\mathrm{MgCl}_{2}$ at final concentrations of $0.3 \%$ and $0.05 \mathrm{M}$, respectively, the DNA was degraded with DNase $(10 \mu \mathrm{g} / \mathrm{ml})$ for $30 \mathrm{~min}$ at $37^{\circ} \mathrm{C}$, and insoluble expression products were washed five times with $0.02 \mathrm{M}$ Tris- $\mathrm{HCl}(\mathrm{pH} 8.0$ ) containing $0.02 \mathrm{M}$ EDTA and $0.5 \mathrm{M} \mathrm{NaCl}$. The washed pellet was dissolved in $8 \mathrm{M}$ urea, clarified by centrifugation, and used for coating microwell plates.

\section{Western blot}

Western blot of the affinity-purified $\mathrm{gE}$ and recombinant $\mathrm{gE}$ was performed as described (Morenkov et al., 1997a).

\section{Indirect gE-ELISAs}

After determining the optimum reagent concentrations by checkerboard titrations and optimising test conditions, the indirect gE-ELISAs were carried out as follows:

ELISA plate wells were coated with an optimum concentration of the affinity-purified or recombinant gE diluted in $0.05 \mathrm{M} \mathrm{Na-carbonate} \mathrm{buffer} \mathrm{(pH} \mathrm{9.6)}$ at $4{ }^{\circ} \mathrm{C}$ overnight. After thorough washing with PBS-T (PBS containing $0.05 \%$ Tween 20) and blocking for 30 min with PBS-T-M (2\% skim milk in PBS-T), the swine sera at dilutions 1:30 were added to the wells. In the affi-gE-ELISA, sera 
were diluted in PBS-T-M; in the rec-gE-ELISA, sera were diluted in PBS-T-M containing a $1 \%$ extract of induced sonicated E. coli $[\mathrm{pGEX}-3 \mathrm{X}]$ to eliminate background. After 2-h incubation at $37{ }^{\circ} \mathrm{C}$, the plate wells were washed and incubated for $1 \mathrm{~h}$ at $37{ }^{\circ} \mathrm{C}$ with peroxidase conjugate against swine immunoglobulins diluted at an optimum concentration in PBS-T-M. The plates were washed five times, and the peroxidase bound to the wells was visualised with a substrate solution $(0.7 \mathrm{mg} / \mathrm{ml}$ orthophenylene diamine hydrochloride and $0.01 \%$ hydrogen peroxide in $0.05 \mathrm{M}$ citrate-phosphate buffer, $\mathrm{pH}$ 5.3). After incubation at room temperature for $10-15 \mathrm{~min}$, the reaction was stopped with $50 \mu 1$ of $1 \mathrm{M}$ sulphuric acid. The optical density of each well was read at $492 \mathrm{~nm}\left(\mathrm{OD}_{492}\right)$.

The cut-off threshold discriminating positive and negative sera was set at $3 \times$ the mean of the $\mathrm{OD}_{492}$ of three clearly negative sera included in each assay [sample/control ratio (S/C) 3.0].

Sensitivity was defined as the percentage of positive samples recorded by the gE-ELISAs with the sera that were positive in the reference gE-ELISA (Svanova Biotech).

Specificity was defined as the percentage of negative samples recorded by the gE-ELISAs with the sera that were negative in the reference gE-ELISA (Svanova Biotech).

In the experiments on titration, serial twofold dilutions of positive sera were made in a clearly negative serum, and the dilutions were analysed in the indirect gE-ELISAs. The results were expressed as the number of twofold titration steps, starting from the initial dilution, that should be made until the S/C values decreased below the cut-off value.

\section{Blocking gE-ELISA}

The direct blocking gE-ELISA for the detection of antibodies against $\mathrm{gE}$ was described earlier (Morenkov et al., 1997b). In the titration experiments, the titres of anti-gE antibodies were expressed as the number of twofold titration steps required for the inhibition to be below the cut-off threshold (40\%).

\section{Results}

\section{Preparation of affinity-purified $g E$}

The gB- and gE-specific "sandwich" assays showed that the passage of the detergent-treated viral fluid through gB- or gE-specific affinity columns efficiently removed $\mathrm{gB}$ or $\mathrm{gE}$, respectively, from the effluent and did not affect the concentrations of other ADV glycoproteins. The gE was selectively eluted from the affinity column at $\mathrm{pH} 10.5-11.0$. The elution at $\mathrm{pH}$ higher than 11.0 
and at low $\mathrm{pH}(2.5-3.5)$ resulted in considerable loss of reactivity of $\mathrm{gE}$ with sera and gE-directed MAbs, indicating the damage of the native structure of $\mathrm{gE}$. The material that eluted at $\mathrm{pH} 11.0$ contained high concentrations of $\mathrm{gE}$ and a very low quantity of $\mathrm{gB}$, which was revealed in very sensitive gE- and $\mathrm{gB}$ specific "sandwich" assays. Though the gE-affinity column was specific, we usually used a gB-affinity precolumn for purification of $\mathrm{gE}$.

The eluted material showed a strong reactivity in indirect ELISA with gEdirected MAbs and sera from ADV-infected swine but produced a weak, if any, reaction with $\mathrm{gB}$ - and $\mathrm{gD}$-directed MAbs and with sera from uninfected swine, either unvaccinated or vaccinated with gE-negative vaccine against AD. In Western blot, sera from ADV-infected swine recognised only a single band in the eluted material, while they recognised many ADV-specific proteins in the precolumn material. MAbs against $\mathrm{gB}$ and $\mathrm{gD}$ also showed no reactivity with the eluted $\mathrm{gE}$ in Western blot. These data indicated a high level of purification of $\mathrm{gE}$. Thus, the reaction of serum with the affinity-purified $\mathrm{gE}$ recorded in the indirect ELISA was due to the presence of antibodies specific to $\mathrm{gE}$ but not to other ADV proteins. Though the leakage of MAb 75/7 from the column usually was very low, if any, we added $0.2 \%$ normal mouse sera to the conjugate to eliminate possible cross-reactivity between anti-swine conjugate and traces of MAbs immobilised to solid phase. After thorough checking for purity, the eluted material was titrated and used for coating microwell plates.

\section{Preparation of recombinant $g E$}

The recombinant protein produced in $E$. coli was in the form of inclusion bodies and could be easily purified by centrifugation. SDS-PAGE revealed that the band of approximately $40 \mathrm{kDa}$ that corresponds to the recombinant $\mathrm{gE}$ constitutes $80-90 \%$ in thoroughly washed inclusion bodies. Several additional minor bands of low and high molecular weight observed in SDS-PAGE (Morenkov et al., 1997a) probably represented the breakdown products and the complexes of the recombinant $\mathrm{gE}$ that were not disrupted during the sample preparation before SDS-PAGE. These derivatives of the recombinant gE could be recognised in Western blot by sera from infected swine and by MAbs directed to conformation-independent epitopes of gE (Morenkov et al., 1997a). The recombinant $\mathrm{gE}$ was not further purified because its purification by chromatography on DEAE-Toyopearl $650 \mathrm{M}$ did not increase the specific signal in the ELISA and only slightly reduced the background. To eliminate potential background caused either by serum antibodies against $E$. coli proteins that may contaminate recombinant $\mathrm{gE}$ or by serum antibodies that cross-react with epitopes of GST, we diluted the sera in PBS-T-M containing a $1 \%$ extract of induced sonicated E. coli $[\mathrm{pGEX}-3 \mathrm{X}]$. 


\section{Specificity and sensitivity of $g E$-ELISAs}

The specificity of detection of gE-directed antibodies by the gE-tests was evaluated using a panel of sera from different serum groups. The results are summarised in Table 1 . In all three gE-tests, three clearly negative sera were included as a reference to determine $\mathrm{S} / \mathrm{C}$ values and inhibition percentages. In both indirect gE-ELISAs, sera from uninfected unvaccinated animals produced $\mathrm{S} / \mathrm{C}$ values comparable to those produced by sera from uninfected swine vaccinated against various swine viral disorders (classical swine fever, parvovirus disease, transmissible gastro-enteritis, enzootic encephalomyelitis), as well as by sera from uninfected swine vaccinated with gE-negative vaccine. In the blocking gE-ELISA, sera from uninfected swine, either unvaccinated or vaccinated against various swine viral disorders, usually produced negative inhibition percentages (that is, they produced OD values higher than OD values of three negative reference sera included in the assay) (Table 1). This was due to the fact that negative reference sera were from swine vaccinated with $\mathrm{gE}$ negative vaccine. Such sera usually produce a non-specific blocking effect (20$30 \%$ ) in the blocking gE-ELISA probably due to the presence of ADV-specific antibodies in sera (non-anti-gE), which sterically hinder the gE-specific conjugate from binding to the epitope of gE. Obviously, the use of such negative control sera in the blocking gE-ELISAs will result in negative inhibition percentages with sera containing no ADV-specific antibodies. The results summarised in Table 1 indicate a high specificity of detection of gE-specific antibodies in all three gE-tests.

The ability of the gE-tests to correctly recognise uninfected swine (specificity) and swine infected with ADV (sensitivity) was determined by using a panel of sera from infected and uninfected swine vaccinated with gE-negative vaccine that produced clear results in the reference gE-test (Svanova Biotech). For the evaluation of the tests, 504 negative sera and 136 positive sera were used. The results are summarised in Table 1 and Fig. 1. Negative sera that did not contain gE-specific antibodies produced a mean $\mathrm{S} / \mathrm{C}$ value of 1.63 (range from 0.41 to 4.47$)$ in the rec-gE-ELISA and $1.48(0.45-4.24)$ in the affi-gEELISA. Positive sera that contained anti-gE antibodies produced in the rec-gEELISA a mean $\mathrm{S} / \mathrm{C}$ value of 4.22 (1.31-9.12); in the affi-gE-ELISA, a mean S/C value was $5.36(2.45-9.56)$. In both indirect gE-ELISAs, the cut-off values discriminating positive and negative sera were chosen at $3 \times$ the mean of the $\mathrm{OD}_{492}$ of three negative reference sera $(\mathrm{S} / \mathrm{C}=3.0)$. With this cut-off, the specificity of the tests was estimated to be $90 \%$ for the rec-gE-ELISA and $94 \%$ for the affi-gE-ELISA. The sensitivity of the tests was estimated to be $80 \%$ for the rec-gE-ELISA and $97 \%$ for the affi-gE-ELISA. 


\section{Table 1}

Results obtained in the affi-gE-ELISA, rec-gE-ELISA, and blocking gE-ELISA with sera from different serum groups

\begin{tabular}{|c|c|c|c|c|c|c|}
\hline & \multicolumn{4}{|c|}{ Sera from swine [mean (range) $]^{*}$} & \multirow[b]{2}{*}{$\begin{array}{l}\text { Specificity } \\
(\%)\end{array}$} & \multirow[b]{2}{*}{$\begin{array}{c}\text { Sensitivity } \\
(\%)\end{array}$} \\
\hline & $\begin{array}{c}\text { Uninfected } \\
\text { unvaccinated }\end{array}$ & $\begin{array}{l}\text { Uninfected } \\
\text { vaccinated } \\
\text { against } \\
\text { swine viral } \\
\text { disorders }\end{array}$ & $\begin{array}{l}\text { Uninfected } \\
\text { vaccinated } \\
\text { with gE- } \\
\text { negative } \\
\text { vaccine }\end{array}$ & $\begin{array}{c}\text { Infected } \\
\text { vaccinated } \\
\text { with gE- } \\
\text { negative } \\
\text { vaccine }\end{array}$ & & \\
\hline rec-gE-ELISA & $\begin{array}{c}1.52 \\
(0.77-3.26)\end{array}$ & $\begin{array}{c}1.79 \\
(0.87-3.98)\end{array}$ & $\begin{array}{c}1.63 \\
(0.41-4.47)\end{array}$ & $\begin{array}{c}4.22 \\
(1.31-9.12)\end{array}$ & 90 & 80 \\
\hline affi-gE-ELISA & $\begin{array}{c}1.28 \\
(0.72-2.95)\end{array}$ & $\begin{array}{c}1.36 \\
(0.68-4.07)\end{array}$ & $\begin{array}{c}1.48 \\
(0.45-4.24)\end{array}$ & $\begin{array}{c}5.36 \\
(2.45-9.56)\end{array}$ & 94 & 97 \\
\hline blocking gE-ELISA & $\begin{array}{c}-29 \\
(-54-3)\end{array}$ & $\begin{array}{c}-22 \\
(-57-9)\end{array}$ & $\begin{array}{c}11 \\
(-17-47)\end{array}$ & $\begin{array}{c}84 \\
(34-99)\end{array}$ & 99 & 98 \\
\hline
\end{tabular}

* In the affi-gE-ELISA and rec-gE-ELISA, S/C values are presented. In the blocking gE-ELISA, the inhibition percentages are presented

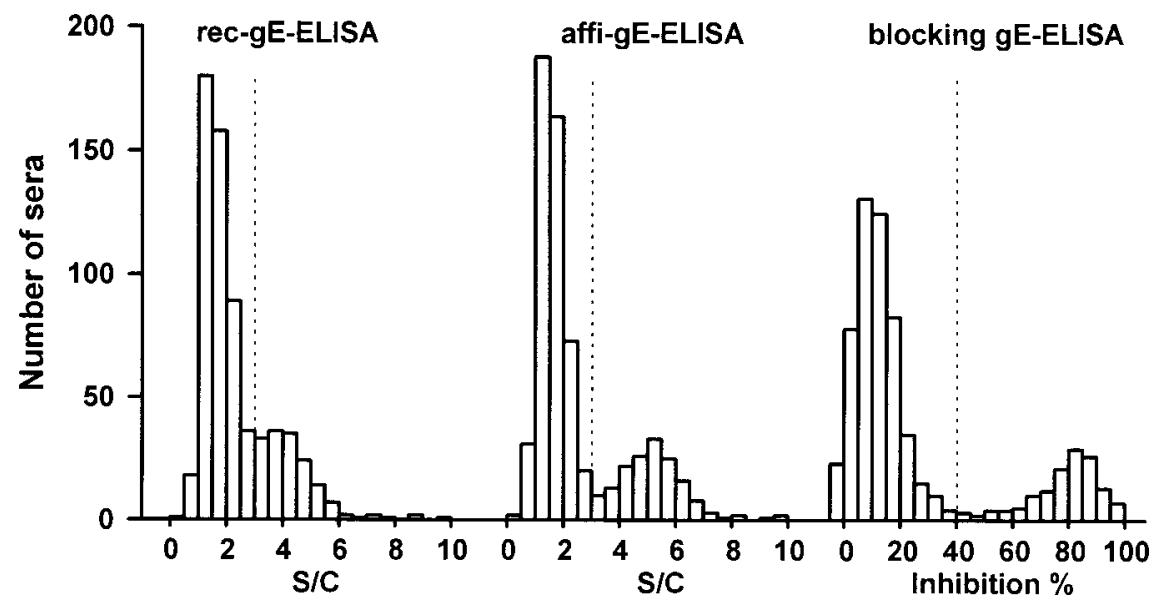

Fig. 1. Distribution of $\mathrm{S} / \mathrm{C}$ values and inhibition percentages of the sera in the indirect and blocking gE-ELISAs. Sera from infected and uninfected swine vaccinated with gE-negative vaccine were used. The vertical dashed lines represent the cut-off values

In the blocking gE-ELISA, the mean non-specific inhibition by negative sera was approximately $11 \%$ (range from $-17 \%$ to $47 \%$ ), while the mean inhibition by positive sera was $84 \%(34 \%-99 \%)$ (Table 1, Fig. 1). Five negative 
sera produced positive results in the blocking gE-ELISA (specificity 99\%) and two positive sera were negative in the blocking gE-ELISA (sensitivity 98\%). It should be noted that one of these two sera that were false negative in the blocking gE-ELISA produced a positive reaction in the affi-gE-ELISA.

Figure 1 shows the distribution of $\mathrm{S} / \mathrm{C}$ values and inhibition percentages of the sera in the indirect gE-ELISAs and the blocking gE-ELISA, respectively. It is seen that the differences between positive and negative sera were more pronounced in the blocking gE-ELISA as compared to those in both indirect gEELISAs. Apparently, the better test performance of the blocking gE-ELISA can be explained by the fact that less sera produced the results close to the cut-off value ("grey zone").

To compare anti-gE antibody concentrations that can be revealed by the gE-ELISAs, a mixture of sera from infected unvaccinated animals was titrated simultaneously in both indirect gE-ELISAs and in the blocking gE-ELISA (Fig. 2). To reach the concentration of anti-gE antibodies that produces the OD values below the cut-off threshold, 7 twofold dilution steps should be made with the mixture of positive sera in the blocking gE-ELISA, and only 4 twofold steps in the affi-gE-ELISA and 3 twofold steps in the rec-gE-ELISA. The diluting of the positive serum started from the initial dilution used in the gE-tests (1:2 for the blocking gE-ELISA and 1:30 for the indirect gE-ELISAs). Similar results were obtained with all positive sera tested (data not shown). This also indicates that the blocking gE-ELISA is more sensitive in the detection of anti-gE antibodies in swine sera than both indirect gE-ELISAs.

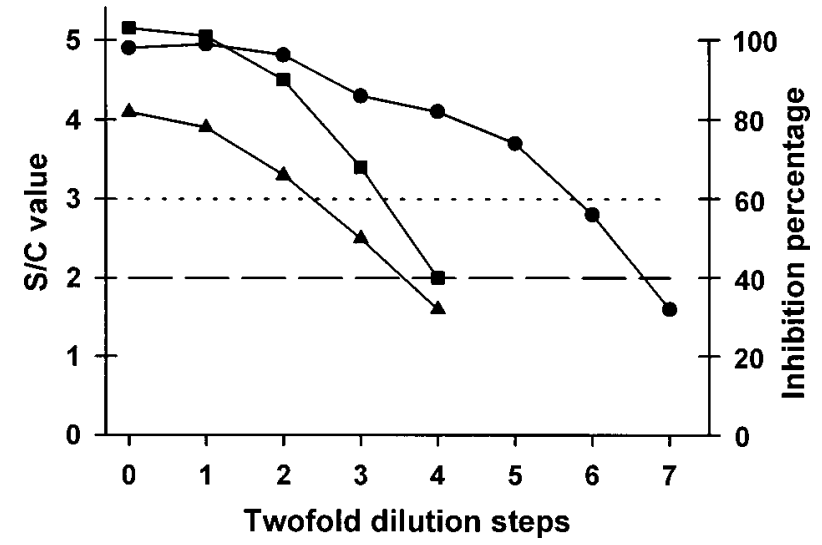

Fig. 2. Titration curves of a mixture of positive sera from the affi-gE-ELISA ( $\mathbf{\square})$, rec-gEELISA ( $\mathbf{\Delta}-\mathbf{\Delta})$, and blocking gE-ELISA $(-\mathbf{O})$. The S/C values (for the affi-gE-ELISA and rec-gE-ELISA) and the inhibition percentages (for the blocking gE-ELISA) are presented. Each figure is a mean value of 3-5 findings. The dotted and dashed lines represent the cut-off thresholds for the indirect $\mathrm{gE}$-ELISAs $(\mathrm{S} / \mathrm{C}=3.0)$ and the blocking gE-ELISA (40\% inhibition), respectively 


\section{Discussion}

The distinction between swine infected with field ADV strains and animals vaccinated with gE-negative vaccine remains of great importance in the control of $\mathrm{AD}$ in countries where vaccination is practised. Most of gE-tests use the principle of blocking ELISA based on one or two MAbs against gE (Eloit et al., 1988; Van Oirschot et al., 1988; Tonelli, 1991; Grom et al., 1992; Morenkov et al., 1997b). The high antigenic drift of gE (Ben-Porat et al., 1986; Mettenleiter et al., 1987; Katz and Pederson, 1992) and the variability of epitopespecific immune response to gE (Jacobs and Kimman, 1994; Jacobs et al., 1994) present a serious problem in the diagnostics of $\mathrm{AD}$ by such tests. Therefore, at present there is a need for a confirmation gE-test which should preferably be based on another principle and should be able to detect antibodies directed against many potential epitopes of gE. Some authors reported the development of such tests based on intact purified $\mathrm{gE}$ or baculovirus-expressed $\mathrm{gE}$ (Mellencamp et al., 1989; Banks et al., 1995; Kimman et al., 1996). Here we describe two indirect gE-ELISAs based on a recombinant fragment of $\mathrm{gE}$ expressed in E. coli (gE-rec-ELISA) and on native affinity-purified gE (gE-affiELISA). The suitability of these indirect gE-ELISAs and the recently developed blocking gE-ELISA (Morenkov et al., 1997b) for diagnostic use was assessed by determining their sensitivity and specificity.

The gE-tests used in eradication programs should be highly sensitive. A relatively lower specificity is acceptable provided that all the infected animals are detected. Taking this into account, we set such cut-off values in the tests that provided a maximum level of sensitivity, which obviously decreased the specificity of the tests.

Recently, we showed that conformation-dependent epitopes of gE play a crucial role in inducing the antibody response to $\mathrm{gE}$ during the natural infection, whereas the contribution of conformation-independent epitopes to the antibody response against $\mathrm{gE}$ is insignificant (Morenkov et al., 1997a). It was also found that $\mathrm{gE}$ retained its native epitope structure during the affinity purification procedure (Morenkov et al., 1997a). The presence of immunodominant conformation-dependent epitopes on the affinity-purified $\mathrm{gE}$ led to a strong reactivity of affinity-purified $\mathrm{gE}$ with positive sera and, as a result, to rather high OD values in the affi-gE-ELISA.

In the rec-gE-ELISA we used a recombinant protein that encompasses the $\mathrm{N}$-terminal sequences of the glycoprotein (Morenkov et al., 1997a). Although the N-terminal part of $\mathrm{gE}$ comprises a cluster of conformation-independent epitopes and is considered to be one of the most important immunodominant regions of the glycoprotein (Fuchs et al., 1990; Jacobs et al., 1990; Morenkov et al., 1997a), the cloned recombinant protein exhibited a relatively weak reactivity 
with sera from infected animals as compared to the affinity-purified gE. This is most probably connected with the lack of immunodominant conformationdependent epitopes on the recombinant $\mathrm{gE}$ protein that induce a strong antibody response during infection of swine. The recombinant protein that was used in the rec-gE-ELISA comprised only conformation-independent epitopes of $\mathrm{gE}$ (Morenkov et al., 1997a), which might be due to incorrect folding of the E. coliexpressed protein. It also cannot be excluded that the lack of conformationdependent epitopes in the $\mathrm{N}$-terminus of $\mathrm{gE}$ is a structural feature of this region in the native glycoprotein.

The major obstacle in the indirect gE-ELISAs is a high non-specific binding activity observed with negative swine sera. As a result, sera could be tested only in relatively high dilutions in the indirect gE-ELISAs $(\geq 1: 30)$ in contrast to the blocking gE-ELISA (dilution 1:2). In the rec-gE-ELISA, the reactivity of serum antibodies with the impurities of bacterial (E. coli) origin and the cross-reactivity with GST presented no problems because undesirable reactivity of the sera was efficiently eliminated by the addition of $E$. coli extract to the sera. It should be noted that the recombinant proteins expressed in $E$. coli often produce a background that is related to the expression system. In the affigE-ELISA, the non-specific binding of antibodies was not caused by the ADVspecific proteins contaminating the affinity-purified $\mathrm{gE}$ because the eluted material was always carefully checked for purity. Only the slight difference in the mean $\mathrm{S} / \mathrm{C}$ values with negative sera from vaccinated and unvaccinated animals in the affi-gE-ELISA (Table 1) confirms a high level of gE purification because ADV-specific antibodies in sera from vaccinated swine (non-anti-gE) virtually did not contribute to the OD values.

The relatively high background with negative sera and the weak specific reaction with positive sera led to a higher frequency of false positive and false negative reactions in the rec-gE-ELISAs and, as a result, to a relatively low test performance (specificity $90 \%$ and sensitivity $80 \%$ ). In the case of the rec-gEELISA, the population of specific antibodies in the serum that are directed to conformation-independent epitopes of the recombinant $\mathrm{gE}$ protein is most probably either small or of poor affinity. In this test, a high sensitivity is accompanied by a low specificity. Due to more pronounced differences between $\mathrm{OD}_{492}$ values of positive and negative sera (Fig. 1), the affi-gE-ELISA provides a more reliable detection of infected animals (specificity 94\% and sensitivity $97 \%$ ) than the rec-gE-ELISA. Titration of positive sera also indicated a higher sensitivity of the affi-gE-ELISA as compared to that of the rec-gE-ELISA (Fig. 2).

Though the indirect gE-ELISAs detect antibodies against many epitopes of $\mathrm{gE}$, in contrast to the blocking gE-ELISA, the blocking test showed a better test performance in terms of sensitivity (98\%) and specificity (99\%) (Fig. 1, Table 1). The experiments on titration of positive sera also showed a higher 
sensitivity of the blocking gE-ELISA as compared to the indirect gE-ELISAs (Fig. 2). The high sensitivity and specificity of the blocking gE-ELISA may be explained by the use of MAb directed to a conservative immunodominant conformation-dependent epitope in the test (Morenkov et al., 1997b), which provides the detection of antibodies against the epitope that induces a strong antibody response during the infection of swine. The higher sensitivity of the blocking gE-ELISA as compared to the affi-gE-ELISA, in which antibodies against many immunodominant conformation-dependent epitopes are detected, is likely to be due to differences in the dilution of sera (1:2 and 1:30, respectively). It is worth noting that one of the two positive sera from our panel that produced false negative results in the blocking gE-ELISA was recognized as true positive in the affi-gE-ELISA. This indicates that with some sera the affigE-ELISA was more sensitive than the blocking gE-ELISA.

Obviously, an efficient discriminative gE-test should detect antibodies to immunodominant conformation-dependent epitopes of $\mathrm{gE}$ that induce a strong antibody response during natural infection of swine. Therefore, binding gEELISAs should be based on proteins that contain such epitopes. The E. coliexpressed recombinant foreign proteins often do not acquire the native epitope structure. The affinity-purified $\mathrm{gE}$ or recombinant proteins expressed in eukaryotic systems appear to be a better choice for such kind of assays. Binding gE-ELISAs are able to detect antibodies against many epitopes, which offers some advantages over blocking gE-ELISAs, especially if the antigenic drift of $\mathrm{gE}$ and the variability of epitope-specific immune responses to $\mathrm{gE}$ are taken into account (Ben-Porat et al., 1986; Mettenleiter et al., 1987; Katz and Pederson, 1992; Jacobs and Kimman, 1994; Jacobs et al., 1994).

In conclusion, two indirect gE-ELISAs based on the affinity-purified and recombinant $\mathrm{gE}$ have been developed. Both tests enable the differentiation of swine infected with ADV from those vaccinated with gE-negative vaccine. The ELISA based on the affinity-purified gE showed a better test performance than the ELISA based on the recombinant fragment of $\mathrm{gE}$ and, in some cases, was more effective in detection of positive sera than the blocking gE-ELISA. The developed indirect gE-ELISAs, in particular the affi-gE-ELISA, can be useful as an additional $\mathrm{gE}$-test in programs of $\mathrm{AD}$ eradication.

\section{Acknowledgements}

We thank Dr. B. Dénes (Central Veterinary Institute, Budapest, Hungary) for supplying sera from swine vaccinated with gE-negative vaccine. We are grateful to Dr. Yu. A. Sobko (Institute of Veterinary Medicine, Kiev, Ukraine) for supplying us with sera from uninfected and ADV-infected swine. Valuable assistance of Dr. Yu. A. 
Mantzyghin in cultivation of viruses is greatly appreciated. We are also grateful to Dr. B. Lomniczi (Veterinary Medical Research Institute, Hungarian Academy of Sciences, Budapest, Hungary) for inspiring discussions. This study was partly supported by the Ministry of Science and Technologies of Russia in the scope of the International RussianHungarian project and by a grant from the Hungarian Scientific Research Fund (OTKA).

\section{References}

Banks, M., Tehranchi, B. and Weightman, S. (1995): Aujeszky's disease ELISA using glycoprotein gE (gI) expressed in baculovirus. In: Schwyzer, M., Ackermann, M., Bertony, G., Koherhans, R., McCullough, K., Engels, M., Wittek, R. and Zanoni, R. (eds) Immunobiology of Viral Infections. Proc. $3^{\text {rd }}$ Congress Eur. Soc. Vet. Virol. pp. 137-141.

Ben-Porat, T., DeMarchi, J. M., Lomniczi, B. and Kaplan, A. S. (1986): Role of glycoproteins of pseudorabies virus in eliciting neutralizing antibodies. Virology 154, 325-334.

Eloit, M., Frageaud, D., Vannier, P. and Toma, B. (1988): Development of an ELISA to differentiate between animals either vaccinated with or infected by Aujeszky's disease virus. Vet. Rec. 124, 91-94.

Fuchs, W., Rziha, H. J., Lucas, N., Braunschweiger, I., Visser, N., Lütticken, D., Schreurs, C. S., Thiel, H. J. and Mettenleiter, T. C. (1990): Pseudorabies virus glycoprotein gI: in vitro and in vivo analysis of immunorelevant epitopes. J. Gen. Virol. 71, 1141-1151.

Grom, J., Linde, N. and Ljung, S. (1992): Monoclonal blocking ELISA detecting Aujeszky's disease virus to the glycoproteins gI and gII. Proc. $12^{\text {th }}$ IPVS Congress, Den Haag, August $17-20$, p. 82.

Jacobs, L. and Kimman, T. G. (1994): Epitope-specific antibody response against glycoprotein E of pseudorabies virus. Clin. Diagn. Lab. Immunol. 1, 500-505.

Jacobs, L., Meloen, R. H., Gielkens, A. L. J. and Van Oirschot, J. T. (1990): Epitope analysis of glycoprotein I of pseudorabies virus. J. Gen. Virol. 71, 881-887.

Jacobs, L., Moonen-Leusen, B. M. W. M., Bianchi, A. T. J. and Kimman, T. G. (1994): Glycoprotein gI of pseudorabies virus: epitope-specific antibody response in mice and pigs. Acta Vet. Hung. 42, 347-351.

Katz, J. B. and Pederson, J. C. ( 1992): Analysis of glycoprotein I (gI) negative and aberrant pseudorabies viral diagnostic isolates. Am. J. Vet. Res. 53, 2259-2266.

Kimman, T. G., de Leeuw, O., Kochan, G., Szewczyk, B., van Rooij, E., Jacobs, L., Kramps, J. A. and Peeters, B. (1996): An indirect double-antibody sandwich enzyme-linked immunosorbent assay (ELISA) using baculovirus-expressed antigen for the detection of antibodies to glycoprotein $\mathrm{E}$ of pseudorabies virus and comparison of the method with blocking ELISAs. Clin. Diagn. Lab. Immunol. 3, 167-174.

Mellencamp, M. W., Pfeifer, N. E., Suiter, B. T., Harness, J. R. and Beckenhauer, W. H. (1989): Identification of pseudorabies virus-exposed swine with a gI glycoprotein enzyme-linked immunosorbent assay. J. Clin. Microbiol. 27, 2208-2213.

Mettenleiter, T. C., Schreurs, C., Thiel, H.-J. and Rziha, H.-J. (1987): Variability of pseudorabies virus glycoprotein I expression. Virology 158, 141-146.

Moormann, R. J. M., DeRover, T., Briaire, J., Peeters, B. P. H., Gielkens, A. L. J. and Van Oirschot, J. T. (1990): Inactivation of the thymidine kinase gene of a deletion mutant of pseudorabies virus generates a safe but still highly immunogenic vaccine strain. J. Gen. Virol. 71, 1591-1595. 
Morenkov, O. S., Mantsyghin, Yu. A., Sergeev, V. A., Sobko, Yu. A., Morenkova, M. A. and Panchenko, O. A. (1994a): Production and characterisation of monoclonal antibodies to glycoprotein gII of Aujeszky's disease virus and their use for gII epitope mapping (in Russian). Voprosy Virusologyi 4, 174-177.

Morenkov, O. S., Mantsyghin, Yu. A., Sergeev, V. A., Sobko, Yu. A., Panchenko, O. A., Zabello, N. E. and Morenkova, M. A. (1994b): The use of monoclonal antibodies for the detection of Aujeszky's disease virus in culture medium by immunoenzyme assay (in Russian). Voprosy Virusologyi 5, 212-215.

Morenkov, O. S., Fodor, N., Sobko, Yu. A. and Fodor, I. (1997a): Immunological characterisation of glycoprotein E of Aujeszky's disease virus. Virus Research 51, 65-79.

Morenkov, O. S., Sobko, Yu. A. and Panchenko, O. A. (1997b): Glycoprotein gE blocking ELISAs to differentiate between Aujeszky's disease-vaccinated and infected animals. J. Virol. Meth. 65, 83-94.

Nauwynck, H. J. and Pensaert, M. B. (1994): Programmes for the eradication of Aujeszky's disease virus (pseudorabies virus) in the member states of the European Union. In: Aujeszky's Disease. O. I. A. Symposium, Bangkok, Thailand, 30 June-1 July, pp. 55-67.

Oppermann, M. (1992): Anion exchange chromatography for purification of monoclonal IgG antibodies. In: Peters, J. P. and Baumgarten, H. (eds) Monoclonal Antibodies. SpringerVerlag, Berlin - Heidelberg, pp. 271-275.

Quint, W. G. V., Gielkens, A. L. J., Van Oirshot, J. T., Berns, A. J. M. and Cuypers, H. T. (1987): Construction and characterization of deletion mutants of pseudorabies virus: a new generation of "live" vaccines. J. Gen. Virol. 68, 523-534.

Ro, L. H., Lai, S. S., Hwang, W. L., Chou, H. H., Huang, J. N., Chang, E. L. and Yang, H. L. (1995): Cloning and expression of an antigenic domain of glycoprotein gE of pseudorabies virus in Escherichia coli and its use as antigen in diagnostic assays. Am. J. Vet. Res. 56, $555-561$.

Stults, N. L., Asta, L. M. and Lee, Y. C. (1989): Immobilisation of proteins on oxidized crosslinked Sepharose preparations by reductive amination. Anal. Biochem. 180, 114-119.

Tonelli, Q. J. (1991): Development and validation of Herdcheck pseudorabies virus gX and gI antibody test kits for use with gene-deleted pseudorabies vaccines. Proc. $1^{\text {st }}$ Int. Symp. Erad. Pseudorabies Virus. St. Paul, University of Minnesota, May 19-22, p. 301.

Van Oirshot, J. T., Houwers, D. J., Rziha, H. J. and Moonen, P. J. L. M. (1988): Development of an ELISA to detect antibodies to glycoprotein I of Aujeszky's disease virus: a method for the serological differentiation between infected and vaccinated pigs. J. Virol. Meth. 22, 191-206.

Wittman, G. (1991): Spread and control of Aujeszky's disease (AD). Comp. Immun. Microbiol. infect. Dis. 14, 165-173. 